\title{
Work Value and Occupational Hazard as Correlates of Organisational Citizenship Behaviour Among Employees of International Brewery Plc. Ilesa, Nigeria
}

\author{
Adeboye Titus Ayinde \\ A. A. Oladoyinbo \\ Department of Psychology, Obafemi Awolowo University, Ile-Ife, Nigeria \\ doi: 10.19044/esj.2016.v12n29p156 URL:http://dx.doi.org/10.19044/esj.2016.v12n29p156
}

\begin{abstract}
The importance of organisational citizenship behaviour can never be over emphasised in organisation striving for competitive advantage. Thus, this study examined employees' organisational citizenship behaviour in relation to factors such as perceived work value, occupational hazard and the combined influence of both factors on organisational citizenship behaviour among employees of International Brewery Plc, Ilesa, Osun State. This is with a view to determining factors that influence organisational citizenship behaviour among workers. Primary data were used for the study. The data were collected from the 269 respondents, which cut across eleven departments: Production, Distribution, Technical, Commercial, Research and Development, Security, Management Information, Quality Assurance, Human Resource, Personnel, Accounting and Audit and Financial department using stratified random sampling technique. Three standardized Psychological Scales were used in the study. These were the Work Value Facet of Personal Life Value Questionnaire (WVFPLV), Organisational Safety Climate Scale (OSCS), Organisational Citizenship Behaviour Checklist (OCB-C). Data collected were analyzed using the appropriate descriptive statistics and inferential statistics.

Results showed a significant relationship between work value and organisational citizenship behaviour among employees of International Brewery Plc, Ilesa $\{\mathrm{r}(267)=0.350), \mathrm{P}<0.05\}$. The result further showed combined significant influence of work value and occupational hazard on organisational citizenship behaviour $\{\mathrm{F}(2,266)=18.81, \mathrm{p}<0.05\}$. However, there was no significant relationship between occupational hazard and organisational citizenship behaviour $\{r=(267)=.050 ; p>0.05\}$. The study
\end{abstract}


concluded that work value has and occupational hazard jointly determined organisational citizenship behaviour.

Keywords: Organisational Citizenship Behaviour, Work Value, Occupational Hazard, Employees, Nigeria

\section{Introduction}

\section{Background to the Study}

In every organization, there are un-statutory behaviours which nevertheless, are important for the progress and development of the organization, and to achieve its stated objectives. This behaviour is not formal as it is neither part of the job description nor part of the other terms of the job. They are behaviours that employee exhibits beyond expected job behaviours. The situation at work can make individual employee elicits citizenship behaviour through learning by model. Though, it is indirectly related to production behaviour but it may go a long way at strengthening the relationship between the organisation and its employees.

Managers strive to minimize dysfunctional behaviours such as; unconcerned attitude while trying to promote organisational citizenship behaviour. Just to consider, a case of an employee who does work that is needed to be done in terms of both quantity and quality. However, failure to work overtime, will not help new employee learn the ropes, and generally unwilling to make any contribution beyond job description and limit. This person may be seen as an assiduous worker, but he is not likely to be seen as a good organisational citizen. Another employee may exhibit a comparable level of performance. He always works late when asked to take time to help new employees learn their way around without complaint, and he is perceived as being helpful and committed to organisation success. He is likely to be seen as a better citizen. Therefore, organisational citizenship may be referred to the behaviour of an individual who makes positive overall contribution beyond the expected roles to an organisation.

Organisational Citizenship Behaviour (OCB) refers to the individual contributions in the workplace that goes beyond role requirements as stipulated in the job agreement (Organ \& Ryan, 1995). Many scholars have claimed that OCB composed of conceptually distinct behavioural dimensions which are approximately 30 in forms that have been developed (Podsakoff, Mackenzie, Paine \& Bachrach, 2000) and generally it can be grouped into seven dimensions known as, (i) Helping Behaviour, (ii) Sportsmanship, (iii) Organisational Loyalty, (iv) Organisational Compliance, (v) Individual Initiative, (vi) Civic Virtue, and (vii) Self Development. OCB has been widely used because it has been found to affect the overall organisational effectiveness (Podsakoff, et al. 2000). 
Meanwhile, it is noteworthy to understand the potential impact of work values on OCB. Work values are defined as attributes inherent in a given job, which individual employee believes organisation should be able to provide (Elegbeleye, 2011). A duty owns by the organisation to its workers, such as duty of care and being valued may serve as the major contributor to the success of the organisation, which may promote citizenship behaviour. A set of values is the moral compass individuals use every day to determine how they should or should not conduct themselves (Suar \& Khuntia, 2010). These values come from an individual's interactions and interpretations of the world around them. An individual is not merely the product of the surrounding environment; there is an inner mind in every human where thoughts influence outward actions and interpretation of the world. Personal experiences and observations influence an individual's world view (Hyde \& Weathington, 2008). Work values encompass policies promoting employees' well-being and feelings of accomplishment, a sense of positive contribution, and behaviour exhibition that is amenable to the attainment of organisational goals. Thus, consequences of work value may include increase positive affect, task interest and performance, and intentions to remain with the organisation.

Occupational hazard was considered in this study because of its propensity in determining organisational citizenship behaviour. Organisation cannot be said to be devoid of accident, workers are daily exposed to series of danger on the job. Condition of work or environment at which work take place at times may not be suitable enough to guarantee safety. How employees viewed what can endanger their safety and lives at works, which determines to a very large extent what one is expected to do and the hazardous nature of the tasks one must perform. It is assumed that an employee will demonstrate pro-social behaviour toward organisation and colleagues at work, especially where safety measure is guaranteed.

\section{Statement of the Problem}

Despite the fact that many organisations in Nigeria have restructured their departments and were able to hire highly qualified and skilled staff, organisational citizenship behaviour has continued to receive poor attention. This may not be unconnected with the fact that people do not want to engage in behaviour where their interest will not be met, even when such is legitimate. This of course, appears to be a common phenomenon in industries. Instead of OCB, issues such as bribery and corruption, lateness to work or absenteeism, mismanagement, dereliction of duties, uncared attitude on the job, wrongful delegation of responsibility at the expense of duty call, high rate of turn- over, seem to be order of the day. Also, some organisations unconcern dispositions toward the welfare of their employees with ripple 
effects on employees' promotion, compensation, etc. A case study is that of Consolidated Brewery Plc, which was sometimes taken over by Nigeria Brewery Plc. Working overtime as also exemplified in the banking sector, and failure to comply with terms and conditions agreed upon. These and others similar cases prompted this study.

There have been several studies on organisation citizenship behaviour, and many of the studies paired the variable with some other predictive variables, such as job satisfaction and organisational performance behaviour (Mehboob \& Bhutto, 2012, Asiedu, Sarfo \& Adjie, 2014). However, there is dearth of study on organisational citizenship behaviour using Brewery industry, where workers' right, entitlement and safety measure seems not well spelt out. Thus, this study posed to examine the extent to which work values and occupational hazard determine organisational citizenship behaviour among employees of International Brewery PLC, Ilsesa, Osun State.

\section{Review of Relevant Theories Expectancy-Value Theory}

Expectancy-Value Theory (Vroom, 1964) is a cognitive-motivational model in which individuals are motivated to strive for or choose a particular goal which is regarded as a 'multiplicative' function of their expectancies and to successfully attain this goal and the subjective valence the individual ascribes to that goal. According to (Feather, 1992) who applied EVT to the context of unemployment, valences may originate from more general values, as values would function as standards or criteria that determine people's attitudes and behaviours. Apart from paying some attention to individuals' valuation of specific job aspects such as opportunities for skill utilisation, variety, and influence, Feather and O'Brien, (1986) contended that most attention within EVT has been paid to the general concept of employment value or employment commitment. The concept of employment value describes a general attachment to work or the general importance ascribed to having a job or being employed (Isaksson, Johansson, Bellaagh, \& Sjoberg, 2004). Employment value is a central aspect of the experience of work because it determines the meaning that work, jobs, and related experiences have for people (George \& Jones, 1997).

Vroom (1964), argued that a person's motivation towards an action would be determined by his anticipated values of all the outcome of the action multiplied by that person's expectancy that the outcome would yield the desired goal. This implies that motivation will take place if:

- $\quad$ The valence or value of the particular outcome is very high for the person. 
- $\quad$ The person feels he has reasonably good choice of accomplishing the task and obtaining the outcome.

Vroom's model identified three major factors which are; Expectancy, Instrumentality and Valence.

According to Vroom (1964), Expectancy; the extent of an individual's perception or belief that a particular act or effect will produce a particular outcome; for example, a person who sees a good work value in an organisation may be prompted to exhibit a pro-social behaviour. Instrumentality on the other hand is the extent at which individuals view relationship between performance and reward. For example, an individual who know that he will receive greater pay or benefits if he produce more has high instrumentality. Lastly, valence is the strength of a person's desire for a particular outcome or reward. It also refers to one perception of the projected outcomes. Generally, when valence is high, motivation is likely to be high. These three factors create a driving force which motivates an individual towards satisfaction and improved performance.

\section{Expectancy Value-Theory implication to the present Study}

This theory is of the opinion that an individual worker or employee would want to exhibit some certain behaviours (at work), based on the value expectation on that job and ability to successfully attain this goal value. It is the central aspect of the experience of work because it gives meaning to what the job has for the employee. It will also affirm that, individual who is unemployed might want to engage in certain behaviours to achieve or get attracted to a particular job and however the flexibility of an individual behaviour to secure a job also depends on work values which individual holds of the job.

Therefore, if an employee perceives that a particular job offers him/her high achievement motivation, realisation of one career development and guarantee of autonomy he or she may imbibe OCB. Giving an ample opportunity to employees to make use of imaginative abilities to create ideas in abstraction and transform them purposely to solve a problem may engender loyalty to the organisation. Helping other people in direct way either individually or in small groups and creates opportunity to have a public contact with people in visible settings and provide job security can shape behaviour of an employee. If the organisation could as well provide or assure the safety of the workers, in terms of a good working condition, this may also enhance employee's disposition to citizenship behaviours. 


\section{Review of Empirical Studies \\ Work Values and Organisational Citizenship Behaviours}

Chen (2011) found a significantly positive correlation between teachers' work values and OCBs at the comprehensive occupational department of a vocational high-school in "A Study on the Relationship between Work Values and Organizational Citizenship Behaviours of Comprehensive Occupational Department Teachers in Senior Vocational Schools". According to Lin (2010) in "A study of the relationship among work values, organizational commitment and organizational citizenship behaviour of elementary school teachers in Yun-Chia area," found that the work values of elementary-school teachers in Yulin and Chiayi Counties are positively correlated to the OCBs. Kao (2011) proved the significantly positive effect of Police College students' work values on psychological contracts and professional commitments, and a similar effect of their psychological contracts and professional commitments on service-oriented OCB in "Work Values and Service-Oriented Organizational Citizenship Behaviour.

The research have shown support for Attraction Selection-Attrition (ASA) model developed by Scheider (1987). The researcher found that employees are more likely to choose organisations with values that match their own values or they are satisfied to work with the organisations that fit with their values. Chatman, Caldwell, and O'Reilly, (1989) who applied the ASA model in his research concluded that employees will not be satisfied to work with an organisation that sets different work values against their own work values. Also, there are many conceptualizations of linkage between work values, needs and organisation citizenship behaviours. Podsakoff, et al. (2000) implied that OCB relates to important work values that will supports an individual's basic and independent needs, when he mentioned organisational behaviour characteristics. One factor which is likely to affect workers' evaluation of organisational work values, is the extent to which organisations are altruistic, supportive, concerned and caring about their general well-being and satisfaction, because organisational citizenship behaviours should be symbiotic between organisations and employees.

The study of work value was first undertaken in order to explain differences in employees' performance and motivation (Hoppe, 1990). Early research into work value was incorporated into early needs theories of motivation such as Maslow's Hierarchy of Needs and Herzberg's distinction between intrinsic and extrinsic needs (Hoppe, 1990). These theories hold as their basic premise, the idea that individuals are motivated to resolve unmet needs (Levy, 2003). Work value based on Maslow's conceptualisation of needs show a correspondence between need and organisational citizenship 
behaviour. Similarly, where job insecurity, anxiety and stress are observed it may lead to a drop in motivation and pro-social behaviour. However, Randall (1993) affirmed that work values should be encourage in any organisation, in order to have a committed workforce, and to be more responsible to one another and to prepare the organisation to be able to function during periods of challenge. Organisational work values are part of a system that fosters a specific organisational culture, and parameters for acceptable behaviour and ethical standards (Edwards \& Cable, 2009; Westerman \& Cyr, 2004).

One persistent distinction in work values is between extrinsic and intrinsic values (Ryan \& Deci, 2000). Extrinsic work values focus on the consequences or outcomes of work - the tangible rewards external to the individual such as income, advancement opportunities, and status, which may facilitate an outward expression of good citizen behaviour. In contrast, intrinsic work values focus on the process of work - the intangible rewards that reflect the inherent interest in the work, the learning potential, and the opportunity to be creative (Ryan \& Deci, 2000), and whenever these values are available in the organisation that enables an employee to be more creative and develop their organizational citizenship behaviours to occur reflectively without much effort.

\section{Occupational Hazard and Organisational Citizenship Behaviour}

The growth of industry in the past three decades, which was brought about by the technological advancement, has consistently rendered Nigerian workers, especially those in the food and beverage industry, susceptible to the risks of work related diseases, injuries and illness. Statistically, workrelated diseases are confirmed to be 160 million every year while more than 2.2 million occupational deaths and 250 million industrial accidents occur every year worldwide (Ajakaye, 2010; International Labour Organisation [ILO], 2011). Due to the capital intensive nature of industries in Nigeria, workers are prone to diverse occupational hazards such as particles, noise, extreme temperature and other reactive chemicals like carbon dioxide, carbon monoxide, and a host of others, which can lead to sudden death of workers and severe health status of others (Omokhodion, 2009; ILO, 2011). Persistent exposure of workers to some of these occupational hazards may affect health as well as impair workers' efforts and affect citizenship behaviour. The consequence of this is that such an organisation will be unable to work at full capacity. However, some studies (Bazas, 2001; Nasab, Ghofranipour, Kazemnejad, Khavanin \& Tavakoli, 2008; ILO, 2011) had shown that the proness of workers to occupational health risks is due largely to their insufficient knowledge on how to manage these and the unsafe behaviour of both employees and organisation. 
Occupational hazard is a major source of morbidity and mortality among all workers (O'Driscoll \& Cooper, 2005). The scopes of safetyrelated duties include informal descriptions of employee job roles which tend to be limited, due to the nature of the work on the office or factory floor. Elements such as reporting minor injuries which allow the organisation to learn and prevent accidents, involve a strong voluntary responsibility. Including behaviour beyond the employee's formal role and are subject to cultural normative influences (Clarke, 2006). Hence, in order to increase the rate of workers' OCBs, it is necessary to create an environment where safety becomes included in their definition of in-role. It holds that OCB on the part of supervisors will engender reciprocal motivations amongst shop-floor employees, with benefits in terms of organisational learning with respect to hazard control performance and employee compliance with safe practice.

Considering the specific conditions that enhance the likelihood of OCBs being imparted by safety emerging, Turner and Pidgeon (2005) showed that employees with higher job demands were less likely to consider safety as part of their role. At the same time, employees with high job control were more likely than employees with low job control to consider safety as part of their role. Hofmann, Morgeson and Gerras (2003) demonstrated that employees will manifest OCBs related to safety only if there is a mature safety climate. In such instances a strong cultural emphasis on safety climate is said to create space for reciprocal behaviours. However, in a context in which there is a high level of LMX against a backdrop of a negative safety climate, OCBs are less likely to extend to the safety agenda naturally (Hofmann, et al. 2003). In addition, Flin, Mearns, O'Connor and Bryden, (2000) report that safety culture is an important factor affecting safety citizenship behaviours.

A lack of control may also diminish the quality of the exchange relationship between employees and employers, and employees to fellow employee thereby reduces or hamper OCB. This may result in a weaker obligation on the part of employee to see the organisation's outcomes as one's own. Indeed, management commitments to safety (Hansez \& Chmiel, 2010) and injury susceptibility (Rickett, Orbell, \& Sheeran, 2006) have been found to be negatively associated with control in past studies. Therefore, it is expected that occupational hazards are negatively associated with organisation citizenship behaviour according to the studies reviewed so far.

\section{Methodology}

\section{Research Design}

This study employed a survey research design. This is adopted because it allowed information to be obtained from a representative sample 
of entire population with a view to examining the influence of work values and occupational hazard (independent variables) on organisational citizenship behaviour (dependent variable).

\section{Study Population}

The population of this study consisted the employees of International Brewery Plc. Ilesha, Osun State. The organisation is made of five hundred and thirty eight workers in different departments (www.sabmiller.com). These departments are: Personnel, Human Resource Management, Quality Assurance, Accounting, Production, Research and Development, Commercial, Logistic, Management information, Security, Finance and Procurement.

\section{Sample and Sampling Procedure}

The Sample for this study was drawn from the employees of International Brewery Plc, Ilesha, Osun State. A stratified random sampling technique was used in selecting the respondents. The organisation was stratified into eleven departments from which the respondents were selected. The total number of the respondents was 269 which represent $50 \%$ of the total population, across all the departments. It comprises males and females, single, married and divorced with the age range between 20 and 50 years, and from junior staff to senior staff members.

\section{Research Instrument}

Work Value Scale (WVS): This is section B of the questionnaire and was assessed using the work value facet of the Personal Life Values scale (PLVS) developed by Hyde and Weathington (2008). This 24-item questionnaire instructs participants to choose the most fitting statement from a group of statement. The format is summated with 5-point likert scale (strongly Disagree, Disagree, Undecided, Agree, Strongly Agree), scored from 1 to 5, respectively. Previous research supports the construct validity of each domain (i.e. work value), For consistency of administration the entire Personal Life Values measures was given to participants although only the work value facet directly related to the proposed hypotheses. Hyde and Weathington (2008) reported acceptable reliability. Within the present study this measure had an overall acceptable reliability coefficient of .78. The pilot study conducted for revalidation of the instrument within the space of two weeks using Cronbach alpha showed reliability .71 and test-retest of .42, .55 consecutively with construct validity.

Occupational Hazard Scale (OHS): Unit safety climate scale was adopted, this is section $\mathrm{C}$ of the questionnaire, for measuring injury and 
illness and was developed by Parker, Turner and Griffin (2003). It has likert format ranging from $1=$ strongly Disagree to $5=$ strongly Agree, which respondents are expected to choose the one applicable to them. The internal consistency reliability of the scale was assessed using estimates of Cronbach alpha. Since safety climate is considered a higher order construct (Griffin \& Neal, 2000), all the 18 items obtained from PCA were used in calculating the reliability of the safety climate scale as a whole. The Cronbach alpha value obtained was 0.76 ; signifying a satisfactorily internal consistency reliability. Likewise, the pilot study conducted using Cronbach alpha showed .67 and test-retest of .23 and .44 consecutively. As evident for discriminate validity, it was expected that respondents' safety climate perceptions would differ according to their work location and position.

Organisational Citizenship Behaviours Scale (OCBS): This is the section D of the questionnaire, original Organizational Citizenship Behaviour Checklist (OCB-C) was a 42 item instrument designed to assess the frequency of organizational citizenship behaviours performed by employees. It has since been refined and shortened to the final 20 item scale that was developed by Fox, Spector Goh, Bruursema and Kessler (2012). The OCB-C was specifically designed to minimize overlap with scale of counterproductive work behaviour, a limitation noted in prior scales (Dalal, 2005). Included were items that reflected acts directed toward the organisation as well as people in the organisation, such as co-workers. Respondents will be rated using a 5-point frequency scale ranging from 1 =strongly Disagree, 2= Disagree, 3= Undecided, 4= Agree, 5= strongly Agree. Scores are computed by summing responses across items. A total score is the sum of responses to all items. The OCB-C is a causal indicator scale that consists of items that are not all parallel assessments of a single underlying construct. Nevertheless, internal consistency reliability (coefficient alpha) was found to be .97. The pilot study conducted as well within two week time frame revealed using Cronbach alpha .60 and with face validity.

\section{Results analysis}

Hypothesis one: The Work values will have a significant positive relationship with organisational citizenship behaviour.

The Pearson Product Moment Correlation was employed to test the hypothesis at $0.05 \%$ significant level. The analysis procedure involves subjecting the respondents' composites scores on work values scale and their corresponding level of organisational citizenship behaviour to a relationship test, the summary of the analysis is presented in Table 1 in appendix page. 
Table 1: PPMC Analysis Showing Relationship between Work values and OCB.

\begin{tabular}{|c|r|r|r|r|r|r|}
\hline Variables & $\overline{\boldsymbol{X}}$ & $S D$ & $N$ & $r$ & $D f$ & $p$-val \\
\hline $\begin{array}{c}\text { Work } \\
\text { Value }\end{array}$ & 93.22 & 12.70 & & & & \\
\cline { 1 - 4 } OCB & 68.26 & 11.12 & 269 & $0.350^{* *}$ & 267 & 0.000 \\
\hline
\end{tabular}

Table 1 indicates that work value has a significant positive relationship with organisational citizenship behaviour $\{r(267)=0.35$, $\mathrm{p}<0.05\}$. Thus, alternate hypothesis which states that there is a significant positive relationship between work value and organisational citizenship behaviour among employees of International Brewery Plc, Ilesha, Osun State is accepted.

Hypothesis Two: There will be a significant positive relationship between perceived occupational hazard and organisational citizenship behaviour.

The study also employed Pearson Product Moment Correlation Coefficient (PPMC) to test the hypothesis at $0.05 \%$ level of significance. The analysis procedure involves subjecting the respondents' score on occupational hazard scale and their corresponding level of organisational citizenship behaviour to a relationship test. The summary of the analysis is presented in Table 2 in appendix page.

Table 2: PPMC Analysis Showing the Relationship between Perceived Occupational Hazard and OCB

\begin{tabular}{|c|r|r|r|r|r|r|}
\hline Variables & $\bar{X}$ & SD & N & r & $D f$ & $p$-val \\
\hline $\begin{array}{c}\text { Occupational } \\
\text { hazard }\end{array}$ & 25.87 & 10.19 & 269 & & & \\
\hline OCB & 68.26 & 11.12 & & .050 & 267 & 0.206 \\
\hline
\end{tabular}

$(\mathrm{p}<0.05)$

Table 2 shows that there was no statistical significant positive relationship between occupational hazard and organisational citizenship behaviour $\{\mathrm{r}(267)=0.50, \mathrm{p}>0.05\}$. Thus hypothesis which states that there will be significant positive relationship between occupational hazard and organizational citizenship behaviour is rejected.

Hypothesis Three: Work value and perceived occupational hazard will have combine significant positive influence on organisational citizenship behaviour. 
The study used multiple regressions to test the hypothesis at $0.05 \%$ level of significance. The analysis procedure involve subjecting the respondents' score on work value, occupational hazard scale, and their corresponding level of organisational citizenship behaviour to a relationship test, the summary of the analysis is presented in Table 3 in appendix page.

Table 3: Multiple regression analysis showing the combined influence of work value and perceived occupational hazard on organisational citizenship behaviour

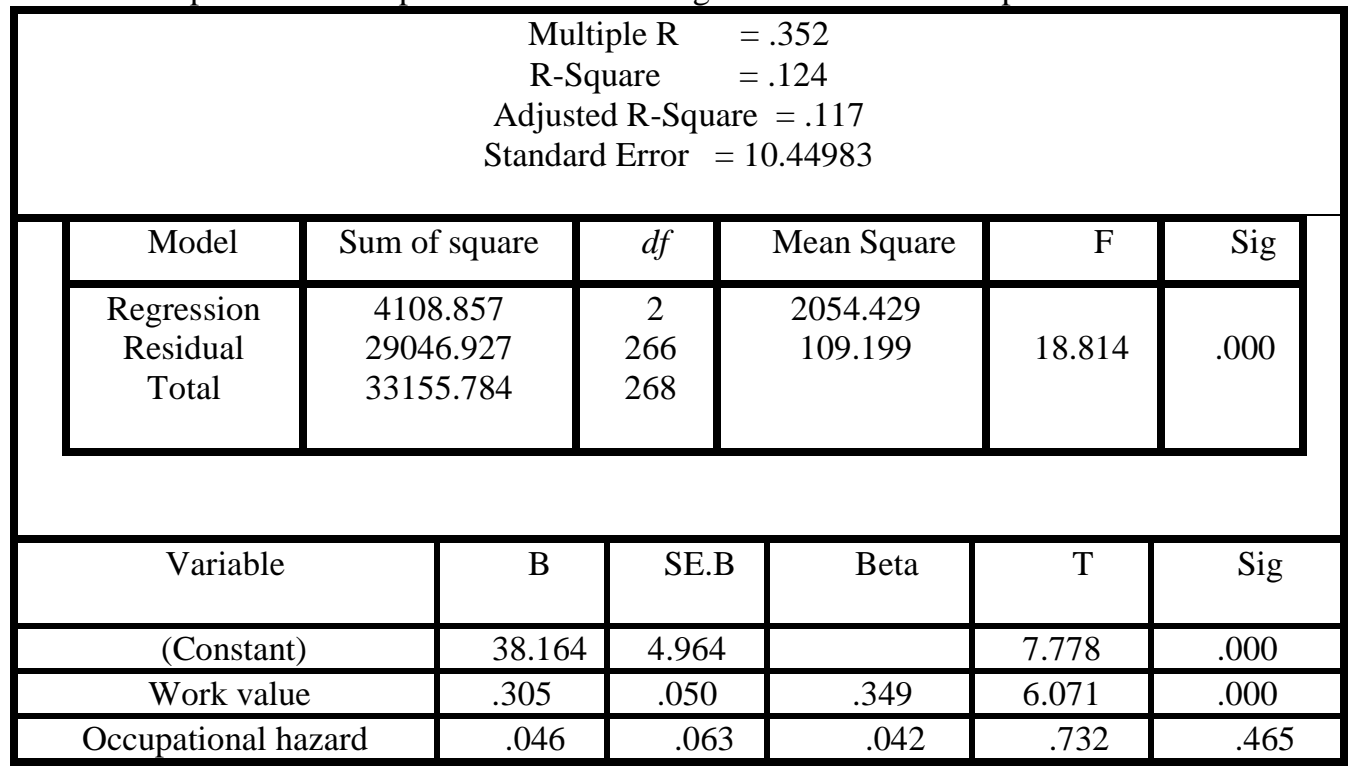

$\left\{\mathrm{F}(2,266)=18.814, \mathrm{p}<0.05, \mathrm{R}^{2}=.124, \mathrm{R}-\right.$ Adjusted $=.117$, Std Error $\left.=10.44983\right\}$

The result in table 3 shows that there is a significant combined influence of work values and occupational hazard on organisational citizenship behaviour $\left\{\mathrm{F}(2,266)=18.814, \mathrm{p}<.005, \mathrm{R}^{2}=.154\right\}$. The $\mathrm{R}^{2=} \cdot 154$ indicates that the independent variables (work value and occupational hazard) explained $15 \%$ variation in dependent variable (organisational citizenship behaviour).

\section{Discussion}

Regarding the hypotheses formulated for this study, the first hypothesis which states that work value will have significant relationship with organizational citizenship behaviour revealed that there was a positive significant relationship between employees' perception of work value and their organizational citizenship behaviour. That is, expression of organisational citizenship behaviour is correlated with workers' perception of work value in International Brewery Plc, Ilesa. The finding of this study is in line with the study of Dose (1997) who found that work values has direct influence on employees' attitudes and citizenship behaviour. The finding of 
Hirschfield and Field (2000) indicated that work centrality (i.e. work values) may shape the individual, because individual with high work value reported higher positive attitudes at work. It could be suggested that those who placed high values on work would report higher levels of positive attitudes. Also in some studies, Chen (2011) mentioned the significant positive correlation between teachers' work value and OCB at the comprehensive occupational department of a vocational high-school. However, Peiro, Garcia-Montalvo, and Gracia (2002) posited that workers who strongly value extensive holidays, little pressure, and job security were more willing to accept underemployment or a job that does not offer the opportunity to use their skills and others who value having responsibility and opportunities to learn were unwilling to accept a job that lacked learning opportunities, but were flexible in accepting a job that would require higher qualifications. Vansteenkiste, et al. (2005) found that holding an extrinsic value orientation as an employee was associated with lower job satisfaction, job vitality, and job commitment and higher exhaustion. The plausible reason for these findings could be adduced to workers higher awareness of benefit of work value, understanding of what constitutes value and the importance of having other things (perquisite) into consideration by the organisation apart from the normal basic salary.

The second hypothesis, which sought for significant relationship between occupational hazard and organisational citizenship behaviour revealed that there was no significant positive relationship between occupational hazard and organizational citizenship behaviour. It showed that workers perception of hazard or safety risk in an organisation will not inhibit their expression of citizenship behaviour in International Brewery Plc, Ilesa. The result was supported by the studies conducted on "management commitments to safety and injury susceptibility" (Hansez \& Chmiel, 2010; Rickett, Orbell, \& Sheeran; 2006), it was found out that occupational hazards are negatively associated with organisational citizenship behaviour. However, the findings contradict the work of Kalejaiye, (2013) who found that occupational hazard had significant relationship with unsafe work conditions. Also in some studies (Bazas, 2001; Nasab, Ghofranipour, Kazemnejad, Khavanin \& Tavakoli, 2008; ILO, 2011), it was found out that there was a positive correlation between poor understanding of hazard and citizenship behaviour. Pun, and Hui, (2002) in their study found significant relationship between safety behaviour and organisational citizenship behaviour. The justification for this finding was based on the fact that employers' understanding that hazardous work environments are associated with poor job involvement, lower overall job satisfaction, and lower organisation commitment of workers. It can also be adduced that people who 
experiment a positive affective feeling of organisational membership are more motivated to engage in pro-social behaviour.

The third hypothesis which sought for the significance combined influence of work value and occupational hazard on organisational citizenship behaviour revealed is a significant combined influence of work values and occupational hazard on organizational citizenship behaviour. This means that perception of work value and safety measure put up in the organisation have propensity to affect citizenship behaviour among workers. This finding was supported by the work of Chadrakumurah (2010) who found that, there are positive relationships between OCB and intrinsic values, while negative relationships are shown between safety control and OCB. This result also is in line with findings by Hofmann, Morgeson, and Gerras, (2003); Zohar, (2000) that employee safety and work value have positive influence on OCB. Moreover, study by Choi, 2007; Liden, Wayne, and Sparrow (1996) revealed that behavioural disposition is associated with the supportiveness of the work environment.

The plausible reason for these findings may not be unconnected with the fact that individual differs in terms of their beliefs about who or what control the outcomes in their lives in terms of work value a job offers and their safety, which can influence their behaviour in workplace. More so, employees in more hazardous contexts may be less likely to perceive the concerned of their organisation for their well-being and in turn, be less concerned with the outcomes of their work and its impact on their organization, creating a low-exchange relationship.

\section{Recommendations}

The findings revealed that there exist a positive relationship between work value and occupational hazard on organisational citizenship behaviour. Hence, it is important for organization to understand the value workers expect in their job and to incorporate them into their system. These values go a long way in determining the commitment of employees to their duty and enhance inter-personal relationship among them and reduce tension or conflict in an organization. All these culminate in to organisational citizenship behaviour among workers. More so, since the present study focused solely on the employees of International Brewery Plc, future researchers seeking extensive data collection may conduct comparative analyses in small, medium, and larger firms with different lines of business. Also, conducting a comparative study of both private and public organisation could also give more insight into the influence of work value, occupational hazard on organizational citizenship behaviour. The consideration of 
enumerated constraint in this study is basically a piece of advice for researchers who want to build on these findings for subsequent studies.

Finally, decision makers, Human resource managers, personnel managers, policy makers and organisational/industrial psychologists should give serious and proper attention to organisational citizenship behaviour. Work value and work safety should not be overlooked and reward system has to be reviewed, especially for employees who demonstrate citizenship behaviour since it enhances effectiveness, efficiency and allows organisation to break even and reduce overhead cost.

\section{References:}

1. Ajakaye, S.O (2010). 'Effective Labour Inspection as Correlate of Decent Work Agenda'. A post-field research paper submitted to the Department of Adult Education. University of Ibadan, Nigeria.

2. Asiedu, M., Sarfo, J.O. \& Adjei, D. (2014) 'Organisational Commitment and Citizenship

3. Behaviour: Tools to Improve Employee Performance; An Internal Marketing Approach European Scientific Journal February 2014 edition vol.10, No.4

4. Bazas, T. (2001). Occupational Health Practice in Greece. Journal of Occupational Health, Vol. 60(10): 3-4.

5. Clarke, S. (2006). Perceptions of organisational Safety; Implications for the development of Safety Culture. Journal of Organisational Behaviour, 20, 185-198.

6. Chadrakumura, R., Paul, R.S. \& Perera,.N. (2010). Impact of work values and ethics on citizenship and task performance in local and foreign invested firms: A test in a developing country context. Birmingham, UK: Aston Business School.

7. Chatman, J. A., Caldwell, D. F., \& O’Reilly, C. A. (1989). Managerial personality and performance: A semi-idiographic approach. Journal of Research in Personality, 33, 514- 545.

8. Chen, C.F. (2011). 'A study on the relationship between work values and organizational citizenship behaviours of comprehensive occupational department teachers in senior vocational schools', MA, Taiwan: Institute of Technical and Vocational Education, National Taipei University of Technology.

9. Choi, J. M. (2007). Change-oriented organizational citizenship behaviour: Effects of work environment characteristics and intervening psychological processes. Journal of citizenship and task performance in local and foreign invested firms: A test in a developing country context. 11th International Human Resource 
Management Conference (pp.1-25). Birmingham, UK: Aston Business School.

10. Dalal, R. S. (2005). A meta-analysis of the relationship between organizational citizenship behaviour and counterproductive work behaviour. Journal of Applied Psychology, 90, 1241- 1255.

11. Dose, J.J. (1997). Work values: an integrative framework and illustrative application to organizational socialization, Journal of Occupation/Organizational Psychology. 70:219-240.

12. Edwards, B. D. \& Cable, S. T.(2009). Relationships between facets of job satisfaction and task and contextual performance. Applied Psychology: An International Review, 57(3), 441-465. doi:10.1111/j.1464-0597.2008.00328.

13. Elegbeleye, O. S. (2011). Work Value Scale (WVS), ISBN 978-978916-147-8, Adeleye publishing Service, Lagos.

14. Feather, N.T. (1992). Expectancy-value theory and unemployment effects. Journal of Occupational and Organisational Psychology, 65, 315-330.

15. Flin, R., Mearns, K., O'Connor, P., Bryden, R., (2000). Measuring safety climate: identifying the common features. Safety Science 34 (1e3), 177e192.

16. Fox, S., Spector, P. E., Goh, A., Bruursema, K., \& Kessler, S. R. (2012). The deviant citizen: Measuring potential positive relations between counterproductive work behaviour and organizational citizenship behaviour. Journal of Occupational and Organizational Psychology, 85, 199-220.

17. George, J., \& Jones, G. R (1997). Experiencing work: Values, attitudes, and moods in context. Human performance Relations, 50, 393-416.

18. Griffin, M. A., \& Neal, A. (2000). Perceptions of safety at work: a framework for linking safety climate to safety performance, knowledge, and motivation. Journal of Occupational Health Psychology, 5, 347-358. doi:10.1037/1076-8998.5.3.347

19. Hansez, k. j. Wheeler, A. R \& Kacmar, K .M. (2010). Leadermember exchange and empowerment: Direct and interactive effects on job satisfaction, Quarterly,20, 371-382.

20. Hirschfeld, R. R. Feild, H. S. (2000). 'General Commitment to Work'. Journal of Organizational Behaviour. 21. 789-800.

21. Hoppe, M. H. (1990). A comparative study of country elites: International differences in work related values and learning and their implications for management training and development. 
Unpublished doctoral dissertation, University of North Carolina at Chapel Hill.

22. Hyde, R. E., \& Weathington, B. L. (2008). The congruence of personal life values and work attitudes. Genetic, Social, and General Psychology Monographs, 132(2), 151-190. Retrieved from http://www.ncbi.nlm.nih.gov/pubmed/17663357

23. ILO (2011). Introduction to Occupational Health and Safety. $\begin{array}{lllll}\text { Retrieved } & \text { February } & 1, & 2 & 011\end{array}$ http://www.actav.itcilo.org/actavenglish/teclearn/osh/intro/inmain.ht m Vol. 43:165-167.

24. Isaksson, K. Johansson, G., Bellaagh, K. \& Sjoberg, A. (2004). 'Work values among the unemployed: Changes over time and some gender differences'. Scandinavian Journal of Psychology, 45, 207-214.

25. Kao RS (2011). Work values and service-oriented organizational citizenship behaviour: the mediation of psychological contract and professional commitment of the case in Taiwan Police College, Ph.D., Taiwan: Department of Business Administration, National Central University.

26. Kalejaiye, .P.O. (2013). Occupational health and safety: Issues, challenges and compensation in

Nigeria. Peak Journal of Public Health and Management Vol.1 (2), pp.16-23.

27. Levy, P. (2003). Industrial/Organizational psychology: Understanding the workplace. Boston: Houghton Mifflin Company.

28. Liden, R. C., Wayne, S. J. and Sparrow, R. T. (1996). An examination of the mediating role of psychological empowerment on the relations between the job, interpersonal relationships, and work outcomes. Journal of Applied Psychology, 85, 407-416.

29. Lin, S. M. (2010). A study of the relationship among work values, organizational commitment and organizational citizenship behaviour of elementary school teachers in Yun-Chia area, MA, Taiwan: Department of Education, National Chiayi University.

30. Mehoob, F. and Niaz, A. B.(2012). Job Satisfaction as a Predictor of Organizational Citizenship Behaviour A Study of Faculty Members. Business Institutes Interdisciplinary Journal of Contemporary Research, 3(9).

31. Nasab, H.S. Ghofranipour, F. Kazemnejad A. Khavanin, A. and Tavakoli, R. (2008). The effect of Safety Education on Petrochemical Workers' Safe Behaviour. European.

32. O'Brien, G., \& Feather, N. (1986). The relative effects of unemployment and quality of employment on the affect, work 
values and personal control of adolescents. Journal of Occupational Psychology, 63, 151-165.

33. O'Driscoll, M. P. \& Cooper, C. L. (1996). Sources and management of excessive job stress and burnout. In P. B. Warr (Ed.), Psychology at Work (pp. 188-223). (4th Ed.) Harmondsworth, England: Penguin.

34. Omokhodion, J. O. (2009). Linking the dominance of house girls in Nigeria households to the girl-child Socialization pattern in Nigeria: Current Research Journal in Social Sciences, (2), pp. 1-3.

35. Organ, D.W. \& Ryan, K. (1995). "A meta-analytic review of attitudinal and dispositional predictors of organizational citizenship behaviour", Personnel Psychology, 48, p.775-802. Organizational Behaviour, 14(2): 177-190.

36. Peiro, J., Garcia-Montalvo, J., \& Gracia, F. (2002). How do young people cope with job flexibility?

37. Demographic and psychological antecedents of the resistance to accept a job with non-preferred flexibility features. Applied Psychology: An International Review, 51, 43-66.

38. Podsakoff, P. M., MacKenzie, S. B., Paine, J. B. \& Bachrach, D. G. (2000). Organizational citizenship behaviors: A critical review of the theoretical and empirical literature and suggestions for further research. Journal of Management, 26(3), 513-563.

39. Pun, .K. F. \& Hui, I.K. (2002). Integrating the safety dimension into quality management system: a process model. Total Quality Management. 13(2): 273-91

40. Randall, D. M., \& Cote, J. A. (1993). Interrelationships of work commitment constructs. Work and Occupation, 18, 194-211.

41. Rickett, B. Orbell, S. \& Sheeran, P. (2006). Social-cognitive determinants of hoist usage among health care workers. Journal of Occupational Health Psychology, 11, 182-196.

42. Ryan, R. \& Deci, E. (2000). The "what" and "why" of goal pursuits: Human needs and the self-determination of behaviour. Psychological Inquiry, 11, 227-268.

43. Schneider, B. Grunnarson, S.K. Niles-Jolly, K. (1987). Creating the climate and culture of success. Organizational Dynamics, Vol.23:1, pp.17-29.

44. Suar, R. \& Khuntia, R. (2010). Influence of personal values and value Congruence on Unethical Practices and Work Behaviour. Journal of Business Ethics 97(3), 443-460.

45. Turner, B. A., \& Pidgeon, N. F. (2005). Man-made disasters. New York: Butterworth-Heinemann. 
46. Vansteenkiste, M., Neyrinck, B., Niemiec, C., Soenens, B., De Witte, H., \& Van den Broeck, A. (2005). On the relations among work value orientations, psychological need satisfaction and job outcomes: A self-determination theory approach. Journal of Occupational and Organizational Psychology, 80, 251-277.

47. Vroom V. (1964). Work and Motivation. New York: Wiley.

48. Westerman, J. W., \& Cyr, L. A. (2004). An integrative analysis of person-organization fit theories. International Journal of Selection and Assessment, 12 (3), 252-261.

49. Zohar, D. (2000). A group-level model of safety climate: Testing the effect of group climate micro accidents in manufacturing jobs. Journal of Applied Psychology, 85(4), 587-596. 